Cómo citar este trabajo: Pozo Rivera, E., \& Rodríguez Moya, J. M $M^{a}$ (2018). Impacto de la crisis en los movimientos migratorios en la comunidad de Madrid (2007-2013). Boletín de la Asociación de Geógrafos Españoles, 77, 229-255. doi: http://dx.doi.org/10.21138/bage.2540

\title{
Impacto de la crisis \\ en los movimientos migratorios \\ en la Comunidad de Madrid (2007-2013)
}

Impact of the crisis on migration in the Community of Madrid (2007-2013)

\author{
Enrique Pozo Rivera \\ epozoriv@ucm.es \\ Juana Ma Rodríguez Moya \\ jumrodri@ucm.es \\ Departamento Geografía \\ Universidad Complutense de Madrid (España)
}

\section{Resumen}

Una consecuencia de la crisis económica ha sido la modificación del modelo migratorio. La reducción de la intensidad de las migraciones y la aparición de saldos migratorios negativos por una emigración exterior creciente que supera la corriente inmigratoria se extiende por gran número de regiones incluida la Comunidad de Madrid. En este artículo se estudia el caso madrileño marcado además por un cambio en la migración interprovincial y una reducción del proceso de expansión periférica metropolitana en consonancia con la reducción de las migraciones internas residenciales que condiciona la aparición de un nuevo modelo demográfico de escaso crecimiento y menor importancia del factor migratorio.

Palabras clave: migraciones; tipos de flujos migratorios; distribución espacial; crisis; Madrid.

\begin{abstract}
One consequence of the economic crisis has been the modification of the country's migratory model. Reducing the intensity of migration together with the emergence of negative migratory


balances which results from external migration surpassing the influx of immigrants, spreads out to many of the country's regions, including the Community of Madrid. This article deals with the study of Madrid's case, having also been marked by a profound change in interprovincial migration and by a reduction in the process of peripheral metropolitan expansion in line with the reduction of residential internal migration, that has yielded the appearance of a new demographic model with little growth and less affected by the migratory factor.

Key words: migration; types of migrations; spatial distribution; crisis; Madrid.

\section{Introducción}

La crisis económica iniciada en 2007 se ha dejado sentir con fuerza en los movimientos migratorios reduciendo la intensidad de la mayoría de los flujos, intensificando algunos que eran muy escasos, cambiando el modelo migratorio imperante antes de la crisis y matizando o incluso modificando las pautas territoriales observables hasta entonces. Además, la reducción de la intensidad de la migración se ha traducido en un menor crecimiento de la población que se debe cada vez más a la dinámica natural, que a la componente migratoria. A estas conclusiones llegan numerosos trabajos en los últimos años. Sin duda, la mayor preocupación se ha centrado en los cambios en los flujos exteriores asociados al aumento del paro y la caída del empleo, destacando la caída de la inmigración extranjera y el incremento de la emigración tanto de extranjeros como de españoles (Aja, Arango, \& Oliver, 2009, 2013; Domínguez, Guerra \& Parreño, 2012; Méndez, Abad \& Echanoves, 2015) señalando, en este último caso, la menor intensidad del flujo de salidas en comparación con la gravedad de la crisis (García \& Pumares, 2014; Van Dalen \& Henkens, 2012) explicable, en parte, por su subestimación en la fuentes estadísticas (González, 2013; Ganau \& Porsche, 2014; Susino, 2012). Mucha menor preocupación han suscitado los cambios en las migraciones internas donde se sigue observando una mayor tasa de migración en los extranjeros que en los españoles (Pozo \& García, 2010; Domingo \& Recaño, 2010; Gil-Alonso, Bayona \& Pujadas, 2015). Junto al descenso de los flujos interprovinciales y el de las migraciones residenciales intraprovinciales, palpable a nivel nacional (García \& Pumares, 2014) y subregional, como sucede en los principales ámbitos metropolitanos del país (Gil-Alonso, Bayona \& Pujadas, 2016), se subrayan cambios en las pautas territoriales de interés. Así, en las migraciones interprovinciales las provincias de Barcelona y Madrid invierten su tradicional saldo negativo en positivo fruto de una mayor resiliencia a la crisis por su estructura productiva más diversificada, presencia de sectores de mayor cualificación y un menor papel redistributivo de los extranjeros (García \& Pumares, 2014). Por otro lado, aumentan las provincias con saldos negativos (García \& Pumares, 2014; Méndez, Abad \& Echanoves, 2015). En las migraciones residenciales su reducción se traduce en una menor suburbanización en los ámbitos metropolitanos (Bayona, Gil-Alonso \& Pujadas, 2012) y en una 
mayor homogeneización de los valores (Pujadas, Bayona \& Gil-Alonso, 2014) que no cambia las pautas tradicionales territoriales de los flujos (Gutiérrez \& Delcrós, 2014).

En este artículo abordamos el análisis de los movimientos migratorios en la Comunidad de Madrid en el periodo 2007 a 2013 marcado por la crisis económica en comparación con el período anterior de fuerte crecimiento de la población y las migraciones. Si bien, para el periodo precrisis en la región madrileña contamos con trabajos sobre la misma cuestión (Pozo \& García 2009, 2010, 2011), para el período más reciente apenas si los hay, limitándose solo a análisis comparativos entre distintas regiones metropolitanas en el ámbito de los flujos residenciales internos (Pujadas, Bayona \& Gil-Alonso, 2014; Bayona \& Pujadas, 2014) y a la ralentización de dichos flujos en algunas comarcas periféricas del sur metropolitano madrileño (Pozo, Rodríguez \& García, 2012) y siempre incluyendo un par de años, a lo sumo, del actual período de crisis. Pero falta un trabajo que analice lo sucedido en todos los tipos de flujos con un horizonte temporal del periodo de crisis significativo, que analice el modelo migratorio madrileño y, que además, proceda al análisis territorial a diferentes escalas para mostrar las desigualdades geográficas del cambio migratorio y todo ello en comparación con el período precrisis para constatar los cambios acaecidos. Son estos los objetivos de este trabajo y para ello el texto se articula en cuatro grandes apartados, además de esta introducción y el epígrafe dedicado a las fuentes de información y metodología, se hace un análisis de la importancia del factor migratorio en el cambio del modelo demográfico, se aborda la evolución de los flujos migratorios y luego las diferencias a escala subregional y municipal en la evolución e intensidad de la migración.

\section{Fuentes estadísticas y metodología}

En este artículo se ha utilizado como fuente los datos de las Estadísticas de Variaciones Residenciales (EVR) aportados por el Instituto de Estadística de la Comunidad de Madrid. Las EVR se elaboran a partir de la explotación de las altas y bajas de los padrones municipales de habitantes motivadas por los cambios de residencia de la población realizados a lo largo de cada año. En ellas, además de las variables sexo y edad, se incluye el origen y el destino del desplazamiento y la nacionalidad, por lo que es posible identificar la movilidad de los españoles y extranjeros y distinguir entre los movimientos exteriores (entradas y salidas desde o hacia el extranjero) y los interiores (internos), diferenciando en estos entre los efectuados entre las distintas provincias y los llevados a cabo en el interior de una misma provincia. El empleo de las EVR no está libre de problemas, ya que al margen de cuantificar desplazamientos y no personas, a veces no hay coincidencia entre el momento del desplazamiento y la tramitación del alta o la baja padronal, hay casos de empadronamientos falsos por distintos motivos (educativos, fiscales...) y limitaciones (subregistro) con las bajas al extranjero, pero el carácter anual de la fuente y la inclusión del origen y destino del desplazamiento permite un conocimiento detallado de la evolución de la migración y sus pautas 
geográficas. Al margen de las EVR, se ha contado con el Padrón de Habitantes, que aporta datos anuales a fecha de 1 de enero y que se han utilizado como población de referencia en las tasas siguientes: migración bruta y neta, inmigración y emigración.

Tanto con los valores absolutos, como con las tasas, se ha trabajado a dos niveles. Por un lado, se ha distinguido entre tres grandes tipos de flujos migratorios: el exterior para los desplazamientos desde y hacia el extranjero, el interprovincial (rotulado en las Tablas como CCAA) para los desplazamientos desde y hacia otras Comunidades Autónomas y el interior que engloba los desplazamientos dentro de la Comunidad de Madrid. Por otro lado, en cada uno de estos tipos se diferencia entre inmigración y emigración distinguiendo entre la población española y la extranjera.

El análisis evolutivo de las migraciones para el conjunto de la Comunidad de Madrid se ha realizado a partir de las cifras anuales, utilizándose los años de 2007 y 2013 para realizar el estudio comparativo (precrisis y crisis) a la escala de las grandes unidades territoriales de la región. A escala municipal este análisis comparativo se ha realizado con los valores medios de los periodos 2005-2007 y 2011-2013 para evitar las distorsiones que pudieran producirse por el empleo de un solo año en ámbitos espaciales reducidos.

La utilización de las EVR no es idónea para fijar el papel del factor migratorio en la evolución de la población por cuantificar desplazamientos y no personas. Por ello, se ha procedido a la obtención del saldo migratorio derivado de la ecuación demográfica, una vez conocida la población total a partir del Padrón de Habitantes y el crecimiento vegetativo, obtenido del Movimiento Natural de la Población del INE de cada uno de los años de los dos períodos considerados en el análisis comparativo (1996-2008 y 2008-2014).

El ámbito espacial del trabajo es la Comunidad de Madrid. El análisis se realiza a escala municipal y comarcal, utilizando en este caso una clasificación espacial propia distinta de la oficial elaborada por el Instituto de Estadística de la Comunidad de Madrid o de las que aparecen en los trabajos que tienen como finalidad la delimitación del Área Metropolitana de Madrid. Estas últimas delimitaciones nos resultan insatisfactorias por insuficientes, ya que solo diferencian entre los municipios considerados como metropolitanos, que difieren en su número según los criterios utilizados en cada trabajo, y los no metropolitanos, sin realizar una clasificación interna en ambos ámbitos (Ministerio de la Vivienda, 2007; Feria, 2010; Roca, Moix \& Arellano, 2012), llegando incluso a considerar como metropolitanos a municipios de las provincias limítrofes. Las clasificaciones oficiales también nos resultan insatisfactorias. La primera se asocia al Plan General del Área Metropolitana de 1963 y la aparición del organismo dependiente del Ministerio de la Vivienda encargado de su gestión (la desaparecida COPLACO) y diferencia entre una Área Metropolitana configurada por la Capital y 27 municipios que conforman la llamada corona metropolitana en la que se distinguen cuatro áreas (norte, sur, este y oeste) y un extenso espacio considerado como no metropolitano en el que no se 
realiza ninguna diferenciación territorial interna. Desde comienzos de este siglo el Instituto de Estadística de la Comunidad de Madrid distingue 11 zonas (NUTS4) con la ventaja respecto a la división territorial anterior que distingue fuera del espacio metropolitano seis zonas (sierra norte, central y sur y nordeste, sudeste y sudoeste de la Comunidad), pero con el problema de incluir en cada zona municipios con características muy diferentes en relación con el grado de transformación de los mismos ante el proceso generalizado desde los años noventa de expansión espacial metropolitana. En la fecha e intensidad de este proceso la distancia al área metropolitana ha jugado un papel esencial al igual que la red viaria, en la que se ha producido el paso de una red radial a otra reticular apoyada en los grandes ejes viarios radiales y orbitales facilitando el proceso de difusión metropolitana. Por ello, en el territorio que se extiende por la Comunidad Autónoma más allá del Área Metropolitana que consideramos periurbano por estar sometido en su totalidad a cambios sociales, económicos, funcionales y morfológicos hacia pautas urbanas, se han delimitado cuatro coronas a partir de los criterios de distancia al área metropolitana y contigüidad espacial entre los municipios en consonancia con la idea de la disminución gradual del proceso de difusión urbana y transformación de los municipios al aumentar la distancia al Área Metropolitana tradicional. Estas cuatro coronas periurbanas se suman así a la Capital y las cuatro áreas (norte, sur, este y oeste) que configuran la corona metropolitana (Figuras 1 y 2).

Figura 1. Áreas de la corona metropolitana de Madrid

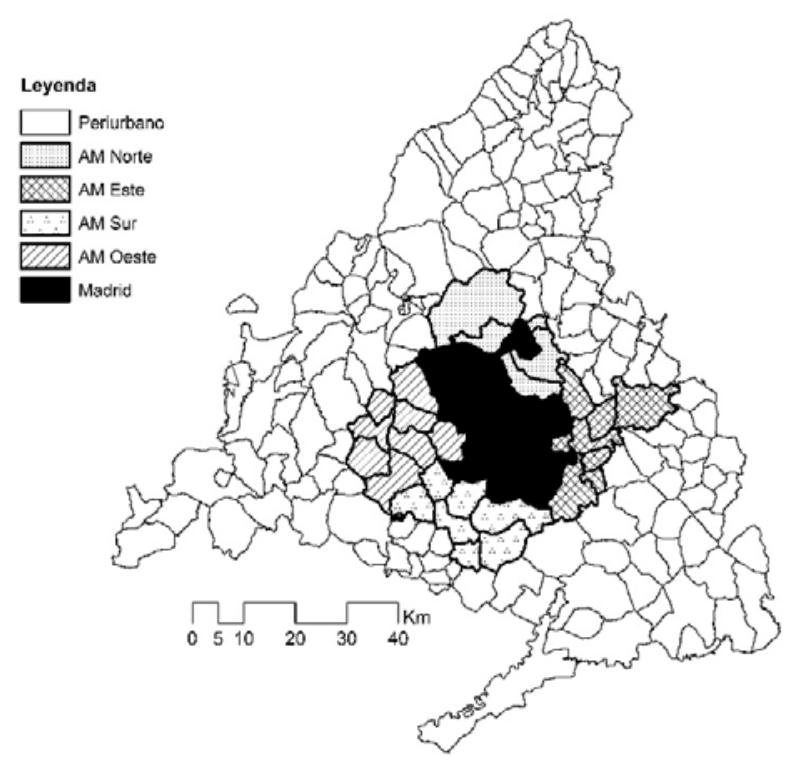

Fuente: elaboración propia 
Figura 2. Corona metropolitana y coronas periurbanas en Madrid

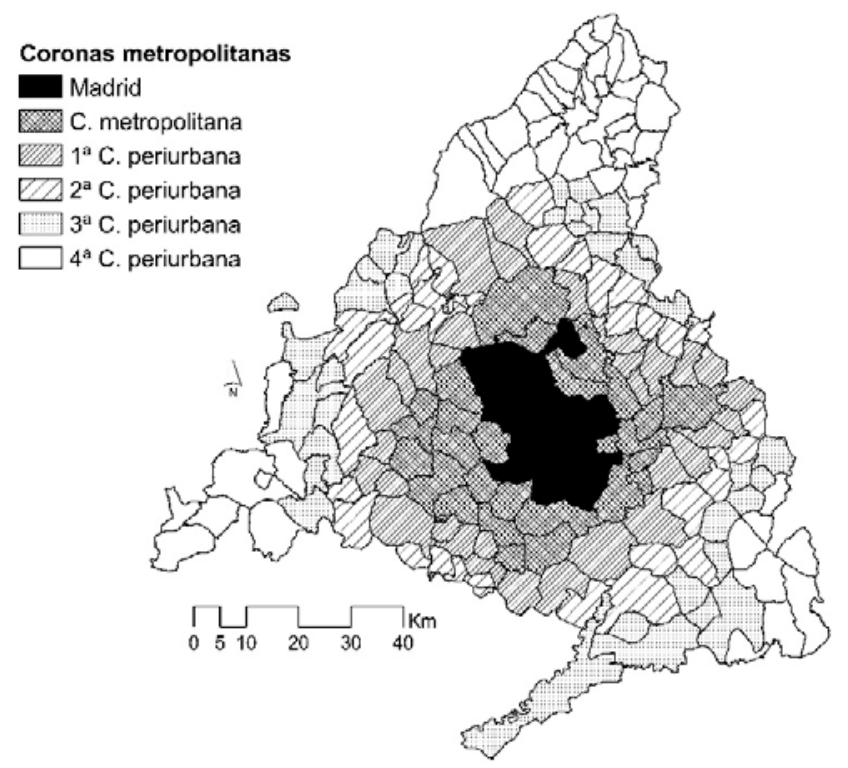

Fuente: elaboración propia

\section{Cambio migratorio y nuevo modelo demográfico en la comunidad de Madrid}

El inicio de la crisis económica vino a romper un modelo demográfico en la Comunidad de Madrid caracterizado por el fuerte crecimiento de la población debido sobre todo al incremento espectacular del saldo migratorio (Tabla 1). En efecto, en el período de fuerte expansión económica de 1996 a 2008, la región sumó 1249349 habitantes, con un ritmo de crecimiento anual medio algo superior al $2 \%$, de los que casi un millón de personas se debieron al factor migratorio. El crecimiento se produjo en todos los grandes ámbitos de la región, incluida la Capital que perdía población desde mediados de los años setenta. En todos los casos el factor migratorio fue la causa principal del crecimiento de la población, ya que sus valores superaron con mucho al crecimiento natural. La mayor intensidad del crecimiento en valores relativos se produjo en el espacio periurbano, donde se concentran la mayoría de los 96 municipios que crecieron con tasas anuales superiores al $5 \%$ y la práctica totalidad de los 39 municipios que sobrepasaron el espectacular $10 \%$ anual de crecimiento, un crecimiento que subraya la extensión del proceso de suburbanización más allá de la tradicional corona metropolitana y que en esa etapa coincide con la recuperación de la población de la Capital, explicable más por la fuerte llegada de inmigrantes extranjeros que por un saldo migratorio de españoles que fue negativo (Bayona, Gil-Alonso \& Pujadas, 2012; Pozo \& García 2009).

La crisis ha abierto un nuevo modelo demográfico definido por un crecimiento menor, un saldo migratorio negativo debido al hundimiento de la inmigración extranjera y el aumento de la emigración al exterior, junto con la consolidación del saldo natural como único factor de 
crecimiento. Un nuevo modelo con diferencias territoriales que se resumen en la reaparición de la caída de efectivos en la Capital, la ralentización del crecimiento en la corona metropolitana, donde el saldo natural es el principal o el único factor del crecimiento y el hundimiento del crecimiento en el espacio periurbano donde aún el saldo migratorio es el principal factor del crecimiento (Tabla 1). El menor crecimiento de la corona metropolitana y del espacio periurbano se explica, no solo por la caída de la inmigración exterior y el aumento de la emigración exterior, sino también, por una menor inmigración interna por las dificultades de acceso a una vivienda impuestas por la crisis que se traduce en una menor intensidad del proceso de suburbanizacíon y de su extensión espacial cada vez más lejos del tradicional espacio metropolitano.

Tabla 1. Evolución de la población en la comunidad de Madrid por grandes zonas geográficas

\begin{tabular}{|c|c|c|c|c|c|c|c|c|c|c|c|c|}
\hline \multirow{2}{*}{$\begin{array}{l}\text { Unidades } \\
\text { territoriales }\end{array}$} & \multicolumn{3}{|c|}{ 1996-2008 } & \multicolumn{3}{|c|}{$2008-2014$} & \multicolumn{3}{|c|}{ 1996-2008* } & \multicolumn{3}{|c|}{$2008-2014$ * } \\
\hline & C. Real & C.Natural & $\begin{array}{l}\text { Saldo } \\
\text { Mig. }\end{array}$ & C.Real & $\begin{array}{c}\text { C. Natur } \\
\text { al }\end{array}$ & $\begin{array}{l}\text { Saldo } \\
\text { Mig. }\end{array}$ & TCR & $\mathrm{TCN}$ & TMN & TCR & $\mathrm{TCN}$ & TMN \\
\hline Madrid & 346421 & 39981 & 306440 & -48036 & 42792 & -90828 & 1,01 & 0,12 & 0,89 & $-0,25$ & 0,22 & $-0,47$ \\
\hline $\begin{array}{l}\text { Corona } \\
\text { Metropolitana }\end{array}$ & 521347 & 46534 & 335047 & 121362 & 98863 & 22499 & 2,54 & 0,23 & 2,31 & 0,91 & 0,74 & 0,17 \\
\hline AM Norte & 66477 & 21520 & 44957 & 22415 & 11095 & 11320 & 2,82 & 0,91 & 1,90 & 1,42 & 0,70 & 0,72 \\
\hline AM Sur & 154659 & 77243 & 77416 & 36673 & 45686 & -9013 & 1,41 & 0,70 & 0,71 & 0,57 & 0,71 & $-0,14$ \\
\hline AM Este & 155330 & 42638 & 112692 & 34159 & 25181 & 8978 & 3,20 & 0,88 & 2,32 & 1,02 & 0,75 & 0,27 \\
\hline AM Oeste & 144881 & 26981 & 117900 & 28115 & 16901 & 11214 & 6,19 & 1,15 & 5,04 & 1,38 & 0,83 & 0,55 \\
\hline \begin{tabular}{|l|} 
Total. \\
Periurbano \\
\end{tabular} & 381581 & 46534 & 335047 & 109476 & 44516 & 64960 & 7,14 & 0,87 & 6,27 & 2,21 & 0,90 & 1,31 \\
\hline $\begin{array}{l}\text { Total C. } \\
\text { Madrid }\end{array}$ & 1249349 & 255042 & 994307 & 182802 & 186171 & -3369 & 2,07 & 0,42 & 1,65 & 0,49 & 0,49 & $-0,01$ \\
\hline
\end{tabular}

Nota: *Tasas anual media de crecimiento real, natural y migración neta en \%

Fuente: elaboración propia a partir del Padrón de Habitantes, Movimiento Natural de la Población de la Comunidad de Madrid (IESTADIS, 1996-2014)

El análisis municipal confirma el cambio de modelo demográfico. Más allá del menor crecimiento, la construcción de una tipología de dinámicas poblacionales (Figura 3) a partir de los componentes de la ecuación demográfica opone la diversidad de dinámicas del período más reciente frente a la homogeneidad del período precrisis por el cambio del factor migratorio. Entre 1996 y 2008 solo un municipio pequeño y aislado perdió población. En el resto de la provincia el incremento demográfico se impuso con el saldo migratorio como principal responsable del crecimiento, reforzado por el saldo natural en la mayoría de los casos (tipo 1), pero con la presencia de crecimiento natural negativo en el caso de municipios muy envejecidos de los tres vértices de la región (tipo 3). Entre 2008 y 2014 son solo 84 los municipios que deben su crecimiento de forma preponderante al saldo migratorio (tipos 1 y 3), aumentando mucho los que crecen más (tipo 2), o solo (tipo 4) por su saldo natural ante la disminución e incluso la inversión del saldo migratorio, que llega en 35 municipios a provocar la aparición de dinámicas regresivas. Estos municipios, que 
pierden población, se reparten entre dos tipos de dinámicas ausentes en el período de 1996 a 2008: la definida por un saldo migratorio negativo que supera a un crecimiento natural negativo (tipo 5), muy extendida por pequeños municipios de la Sierra Norte madrileña, y la que se caracteriza por un saldo migratorio negativo y uno natural positivo (tipo 8), muy presente dentro del ámbito metropolitano (Madrid, Alcalá de Henares, Móstoles y Coslada).

Figura 3. Tipología de dinámicas demográficas 1996-2008 y 2008-2014
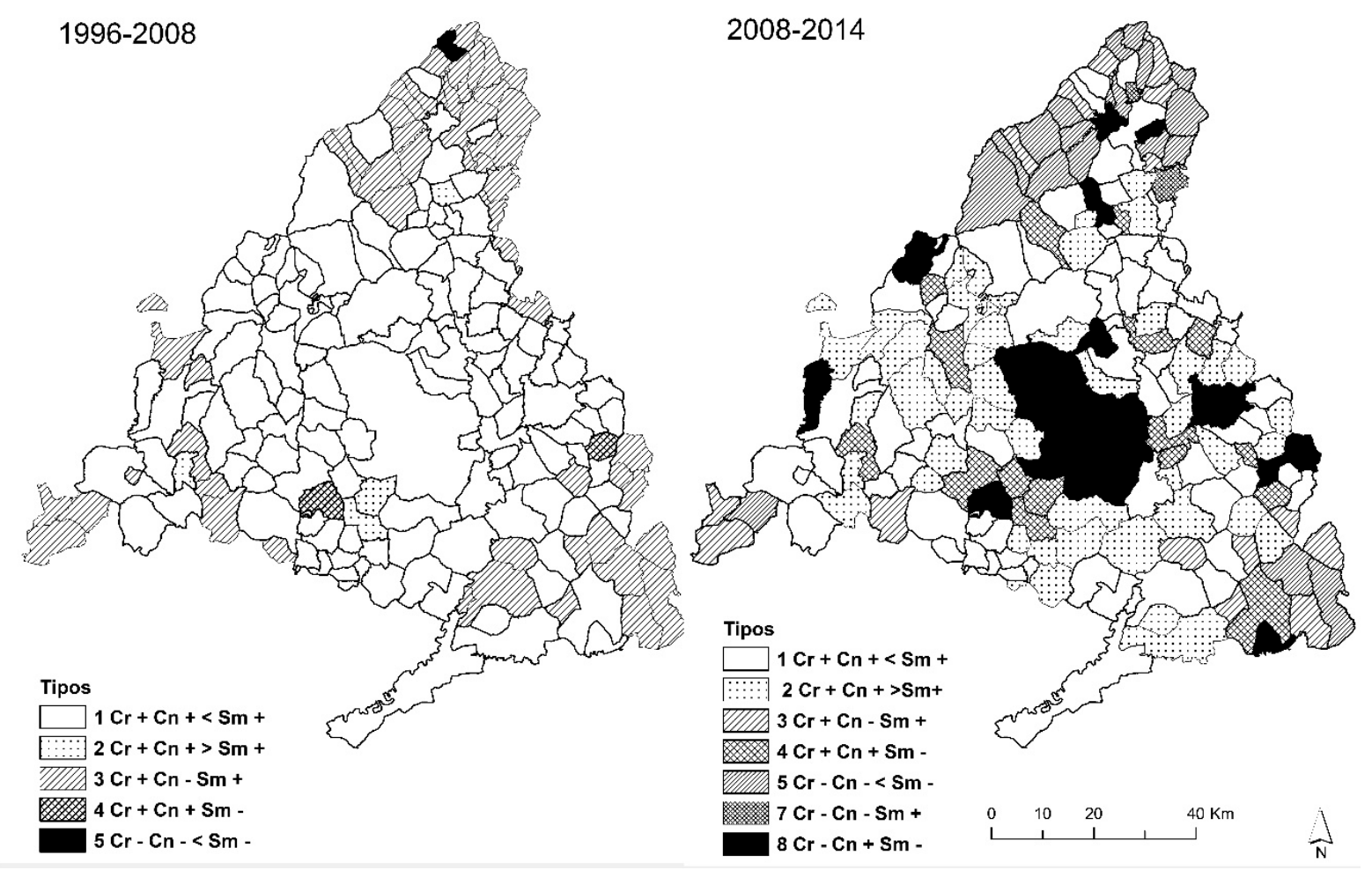

Fuente: elaboración propia a partir del Padrón de Habitantes, Movimiento Natural de la Población (Instituto de Estadística de la Comunidad de Madrid, 1996-2014)

\section{La crisis económica y la evolución de los flujos migratorios}

El fuerte crecimiento de los flujos migratorios en la Comunidad de Madrid fue una constante durante el ciclo expansivo económico que se abrió a mediados de los años noventa. En efecto, tanto el número total de migrantes, como el de los principales flujos inmigratorios y emigratorios con relación al extranjero y el resto de las comunidades autónomas, y los migrantes internos en la Comunidad de Madrid, aumentaron de forma progresiva hasta alcanzar los valores más elevados en 2007, antes de la crisis económica. Así mismo, la tasa bruła de migración también conoció un incremento hasta 2007 en el que se alcanzó el valor máximo. A partir de 2008 los datos invierten su tendencia. Al ciclo económico expansivo, le sucede el inicio de otro recesivo que lleva consigo una caída de los flujos migratorios en general, por el decrecimiento de la actividad y el aumento 
espectacular del paro, que ataca a uno de los motores relacionados con la movilidad como es el empleo y por la intensa crisis del mercado inmobiliario, que es esencial para explicar la disminución de la movilidad residencial en Madrid y las provincias limítrofes castellano manchegas (Tabla 2).

Tabla 2. Evolución de migrantes, inmigrantes y emigrantes por tipo de flujos.

\section{Comunidad de Madrid}

\begin{tabular}{|l|r|r|r|r|r|r|r|r|r|}
\hline Año & $\begin{array}{c}\text { Inmigrantes } \\
\text { Extranjero }\end{array}$ & $\begin{array}{r}\text { Emigrantes } \\
\text { Extranjero }\end{array}$ & $\begin{array}{c}\text { Inmigrantes } \\
\text { CCAA }\end{array}$ & $\begin{array}{c}\text { Emigrantes } \\
\text { CCAA }\end{array}$ & $\begin{array}{c}\text { Migrantes } \\
\text { Internos }\end{array}$ & $\begin{array}{c}\text { Migrantes } \\
\text { Extranjero }\end{array}$ & $\begin{array}{c}\text { Migrantes } \\
\text { CCAA }\end{array}$ & $\begin{array}{c}\text { Total } \\
\text { Migrantes }\end{array}$ & $\begin{array}{l}\text { Tasa bruta } \\
\text { Migración }\end{array}$ \\
\hline 1998 & 14086 & sd* & 39798 & 47222 & 93827 & 14086 & 87020 & 194933 & 38,29 \\
\hline 1999 & 29656 & sd & 44038 & 52222 & 96260 & 29656 & 94232 & 222176 & 43,18 \\
\hline 2000 & 137165 & sd & 45831 & 52172 & 96411 & 137165 & 98003 & 331579 & 63,70 \\
\hline 2001 & 134909 & sd & 45581 & 55329 & 97023 & 134909 & 100910 & 332842 & 61,95 \\
\hline 2002 & 141954 & 7550 & 61761 & 79869 & 131863 & 149504 & 141630 & 422997 & 76,53 \\
\hline 2003 & 128342 & 6989 & 65679 & 93535 & 141469 & 135331 & 159214 & 436014 & 76,24 \\
\hline 2004 & 119315 & 8098 & 66523 & 99854 & 145934 & 127413 & 166377 & 439724 & 75,75 \\
\hline 2005 & 122476 & 8887 & 68676 & 98670 & 146490 & 131363 & 167346 & 445199 & 74,65 \\
\hline 2006 & 163253 & 26238 & 83613 & 107155 & 165835 & 189491 & 190768 & 546094 & 90,89 \\
\hline 2007 & 179608 & 54443 & 98913 & 115451 & 168102 & 234051 & 214364 & 616517 & 101,37 \\
\hline 2008 & 135157 & 60965 & 91770 & 102143 & 152198 & 196122 & 193913 & 542233 & 86,46 \\
\hline 2009 & 87648 & 56411 & 93041 & 95241 & 158469 & 144059 & 188282 & 490810 & 76,85 \\
\hline 2010 & 73390 & 69353 & 93736 & 94753 & 160544 & 142743 & 188489 & 491776 & 76,14 \\
\hline 2011 & 76724 & 95905 & 99129 & 90752 & 153273 & 172629 & 189881 & 515783 & 79,48 \\
\hline 2012 & 67929 & 80363 & 100791 & 85405 & 148359 & 148292 & 186196 & 482847 & 74,30 \\
\hline 2013 & 62472 & 98637 & 95045 & 80042 & 143483 & 161109 & 175087 & 479679 & 73,85 \\
\hline
\end{tabular}

Nota: *(sd) Sin datos oficiales EVR hasta 2002.

Fuente: elaboración propia a partir de Estadísticas del Movimiento Migratorio de la Comunidad de Madrid (IESTADIS, 1998-2013)

Los datos de distintos indicadores económicos son significativos de la mala situación económica desde 2007. En la Comunidad de Madrid hay 377336 afiliados menos en 2013 que en 2007 (2672 138 y 3040474 respectivamente: EPA $4^{\circ}$ trimestre) y 469700 parados más (685 000 y 215300 en 2013 y 2007 respectivamente), con una tasa de paro que ha crecido entre esos dos años del 6,41\% al 20,45\%; y todo ello, como corolario de una desaceleración económica notable porque se ha pasado de una variación interanual positiva del PIB del 4,1\% en 2007 a un decrecimiento del -1,6\% en 2013, con una pérdida de unidades productivas de 146607 (813816 y 667209 en 2007 y 2013) (Colectivo Empresarial, Instituto de Estadística de Madrid). A ello se suma la componente inmobiliaria de la crisis con caídas espectaculares desde el año 2006 a 2013 en el número de licencias concedidas (6820 y 1064), viviendas previstas según licencias (61 687 y 6140) y transacciones de vivienda nueva realizadas (30 633 y 5397).

Esta mala situación económica e inmobiliaria ha influido en una caída de los flujos migratorios y de las tasas de migración (Tabla 2). El número de migrantes ha caído en 136839 desde 2007, un 
descenso del 22,2\%, e igualmente ese descenso se aprecia en la tasa de migración que ha pasado del 101,37\%o en 2007 al 73,84\%o en 2013.

El análisis de la tendencia a la baja de las migraciones permite señalar dos cuestiones de interés: un comportamiento dispar según la nacionalidad y la aparición de tendencias diferentes, tanto en el ritmo total del descenso, como en el tipo de evolución según el flujo migratorio considerado.

En primer lugar, la nacionalidad impone una doble diferenciación en las migraciones (Tabla 3). Por un lado, la tasa migratoria de los extranjeros es muy superior a la de los españoles, tanto antes de la crisis, como durante la misma. La mayor movilidad de los extranjeros se relaciona con la juventud del colectivo, con la escasez de responsabilidades familiares que facilita la movilidad geográfica en relación con la situación del mercado de trabajo, con la temporalidad de buena parte del empleo ocupado por los extranjeros (Pozo \& García, 2011) y con el deseo de mejora residencial asociado al reagrupamiento familiar, al proceso de formación de una nueva familia (Recaño, 2002, 2009a, 2009b) o a la salida de una situación inicial de provisionalidad residencial asociada a una entrada reciente en el país (Gil-Alonso, Bayona \& Pujadas, 2015). Por otro lado, se ha producido con la crisis una caída mucho mayor de la movilidad entre los extranjeros. Así, mientras que en éstos de 2007 a 2013 la caída fue nada menos que de un 36,7\%, entre los españoles fue tan solo un 2,6\%. La diferencia también se aprecia en la evolución de la tasa de migración, ya que si en los extranjeros la caída fue de 144 puntos, en los españoles se ha reducido solo a 5 puntos, y en el análisis según los tipos de flujos, ya que se observa en la migración interna y en la interprovincial (tanto en la inmigración como en la emigración) y sobre todo en la migración exterior donde la diferencia en el descenso por nacionalidad es máxima en la inmigración y menor, en este caso dentro de una tendencia al ascenso también diferenciada por nacionalidad, en la emigración, y eso que muchas de las salidas son de antiguos extranjeros nacionalizados españoles.

La mayor caída en los extranjeros se relaciona con una incidencia más notable de la crisis en ese colectivo. Baste señalar que desde 2007 a 2013 la caída de la afiliación fue el doble en los extranjeros (-22,1\%) que en los españoles (-10,75\%), o que en 2013 (EPA $4^{\circ}$ Trimestre) la tasa de paro es 15 puntos más alta entre los primeros (33,01\% y 18,23\% respectivamente). Pues bien, la mala situación económica provoca una reducción de la oferta de trabajo y por ello en la migración exterior una disminución de las entradas de extranjeros y un incremento de las salidas por la fuerte incidencia de la crisis en los sectores de fuerte empleo extranjero. Además, la crisis limita los desplazamientos internos e interprovinciales por tres razones: la menor llegada de extranjeros desde el exterior se traduce en una disminución del tradicional papel madrileño redistribuidor de extranjeros en el interior del país; las dificultades en el acceso a la vivienda reduce las migraciones residenciales de extranjeros ligadas al proceso de suburbanización madrileño y por último, la peor situación laboral en otras provincias dificultaría los flujos laborales de salida desde Madrid. 
Tabla 3. Migrantes, inmigrantes y emigración por nacionalidad. Comunidad de Madrid

\begin{tabular}{|c|r|r|r|r|r|r|r|}
\hline $\begin{array}{c}\text { Extranjeros } \\
\text { años }\end{array}$ & $\begin{array}{c}\text { Migrantes } \\
\text { Internas }\end{array}$ & $\begin{array}{l}\text { Inmigr. } \\
\text { CCAA }\end{array}$ & $\begin{array}{c}\text { Emigr. } \\
\text { CCAA }\end{array}$ & $\begin{array}{l}\text { Inmigr. } \\
\text { Exterior }\end{array}$ & $\begin{array}{c}\text { Emigr. } \\
\text { Exterior }\end{array}$ & $\begin{array}{c}\text { Total } \\
\text { Migrantes }\end{array}$ & TMB\%o \\
\hline 2003 & 38052 & 16490 & 24981 & 121296 & 2671 & 203490 & 342,50 \\
\hline 2004 & 42630 & 18784 & 29438 & 112639 & 5233 & 208724 & 296,76 \\
\hline 2005 & 46339 & 21198 & 29434 & 116050 & 4626 & 217647 & 281,26 \\
\hline 2006 & 54999 & 25542 & 31221 & 156184 & 20938 & 288884 & 363,84 \\
\hline 2007 & 59031 & 32739 & 41507 & 172276 & 47661 & 353214 & 376,89 \\
\hline 2008 & 54726 & 29805 & 36008 & 128073 & 52770 & 301382 & 299,77 \\
\hline 2009 & 59107 & 30733 & 31902 & 80752 & 47985 & 250479 & 235,46 \\
\hline 2010 & 54953 & 27907 & 29872 & 65410 & 60171 & 238313 & 220,67 \\
\hline 2011 & 51470 & 26692 & 29520 & 67504 & 82738 & 257924 & 241,60 \\
\hline 2012 & 48679 & 26458 & 24636 & 59484 & 66504 & 225761 & 222,41 \\
\hline 2013 & 43446 & 24452 & 20741 & 53643 & 81079 & 223361 & 232,64 \\
\hline
\end{tabular}

\begin{tabular}{|c|r|r|r|r|r|r|r|}
\hline $\begin{array}{c}\text { Españoles } \\
\text { años }\end{array}$ & $\begin{array}{c}\text { Migrantes } \\
\text { Internas }\end{array}$ & $\begin{array}{l}\text { Inmigr. } \\
\text { CCAA }\end{array}$ & $\begin{array}{l}\text { Emigr. } \\
\text { CCAA }\end{array}$ & $\begin{array}{c}\text { Inmigr. } \\
\text { Exterior }\end{array}$ & $\begin{array}{c}\text { Emigr. } \\
\text { Exterior }\end{array}$ & $\begin{array}{c}\text { Total } \\
\text { Migrantes }\end{array}$ & TMB\%。 \\
\hline 2003 & 103417 & 49189 & 68554 & 7046 & 4319 & 232525 & 45,37 \\
\hline 2004 & 103304 & 47739 & 70416 & 6676 & 2865 & 231000 & 45,28 \\
\hline 2005 & 100151 & 47478 & 69236 & 6426 & 2261 & 225552 & 43,46 \\
\hline 2006 & 110836 & 58071 & 75934 & 7069 & 5300 & 257210 & 49,33 \\
\hline 2007 & 109071 & 66174 & 73944 & 7332 & 6782 & 263303 & 51,18 \\
\hline 2008 & 97472 & 61965 & 66135 & 7084 & 8195 & 240851 & 45,73 \\
\hline 2009 & 99362 & 62308 & 63339 & 6896 & 8426 & 240331 & 45,15 \\
\hline 2010 & 105591 & 65829 & 64881 & 7980 & 9182 & 253463 & 47,12 \\
\hline 2011 & 101803 & 72437 & 61232 & 9220 & 13167 & 257859 & 47,56 \\
\hline 2012 & 99680 & 74333 & 60769 & 8445 & 13859 & 257086 & 46,88 \\
\hline 2013 & 100037 & 70593 & 59301 & 8829 & 17558 & 256318 & 46,30 \\
\hline
\end{tabular}

Fuente: elaboración propia a partir de Estadísticas del Movimiento Migratorio de la Comunidad de Madrid (IESTADIS, 2003-2013)

La segunda cuestión hace referencia a las diferencias en la evolución reciente de los migrantes según el tipo de flujo. En general, por grandes grupos de flujos la caída de los migrantes es mucho mayor en el flujo exterior en valores absolutos y relativos (-72942 y -31,16\% de 2007 a 2013) que la sufrida por la migración interprovincial (-39 277 y -18,32 \%) y la sufrida por el flujo interno (-24 619 y -14,64\%), reproduciéndose el mismo esquema en la evolución de las tasas de migración.

El desglose de la evolución por tipos específicos de flujos muestra descensos por encima de la media general en el caso de la inmigración desde el extranjero que se hunde en un 65,2 \% entre 2007 y 2013, y en la emigración a otras provincias que lo hace en un 30,7\%. Evidentemente, en el primer caso, la crisis disminuye el poder de atracción de España y la Comunidad de Madrid, pero aun así no se corta el flujo inmigratorio, fundamentalmente de extranjeros, por motivos laborales, a los que se añaden las entradas relacionadas con la reagrupación familiar. En el segundo caso, la mejor situación económica de la región madrileña con respecto a otras comunidades es posible que ralentice los desplazamientos a las mismas por motivos laborales, a lo 
que se añade una disminución de los cambios residenciales a las provincias limítrofes castellano manchegas. La mejor situación económica relativa de Madrid se traduciría en la práctica estabilización de la inmigración desde otras regiones, provocando que el saldo migratorio de la región con el resto de España pase a ser positivo desde 2011, al contrario de lo que sucedía en el pasado. Por último, no todos los flujos migratorios ven disminuir sus efectivos, ya que se incrementa de forma notable la emigración al extranjero. Este flujo inicia su aumento antes de la crisis, pero sin duda se acelera con ella y sobre todo desde 2010, con un crecimiento del 81,1\% desde 2007. Esta es una migración compuesta mayoritariamente por extranjeros (81 079 en 2013), pero también y de forma creciente de españoles (17558 en 2013) de origen extranjero (nacionalizados) o español, que se ven forzados a salir de España ante la mala situación del mercado de trabajo.

\section{Un nuevo modelo migratorio con saldos negativos}

La crisis económica ha incidido en un descenso acusado de las migraciones en valores absolutos y relativos y ha provocado cambios notables en el modelo migratorio de la Comunidad de Madrid.

En primer lugar, se ha roto una tendencia iniciada a mediados de los años noventa de saldos migratorios positivos (Tabla 4). Desde 2007 se inicia una dinámica de descenso de los saldos que acaban por presentar valores negativos en 2011 y 2013 en un contexto marcado por la caída creciente de la inmigración y el aumento de la emigración. Este saldo que es cada vez menor, e incluso se convierte en negativo, hace que el crecimiento actual de la población de la Comunidad de Madrid se deba según los años más, o solo, al crecimiento vegetativo que al saldo migratorio, al contrario de lo que sucedió antes de la crisis.

Esta tendencia al descenso del saldo migratorio oculta dos hechos de gran interés (Tabla 4). El primero es un comportamiento dispar del saldo por nacionalidad, que invierte la situación anterior a la crisis. Así, el saldo migratorio de los extranjeros, que era antes positivo, se torna cada vez más escaso para acabar siendo negativo desde 2011. Efectivamente, la crisis ha reducido mucho las entradas desde el extranjero, pero además ha disparado las salidas, que serían aún más elevadas si tenemos en cuenta la creciente cuantía de salidas de españoles antiguos extranjeros nacionalizados. En cuanto al saldo de los españoles, el antiguo saldo negativo se torna en positivo a pesar del incremento de las salidas al extranjero, por la caída de la emigración y el aumento de la inmigración interprovincial. El segundo hecho es un cambio en el signo de los saldos migratorios interprovincial y exterior. Antes de la crisis los saldos eran respectivamente negativo y positivo. En cuanto al saldo interprovincial, en el pasado la región constituía la puerta de entrada para muchos extranjeros que luego se distribuían por el resto del país y entre los españoles dominaban las salidas a otras provincias por la suma de flujos como los de retorno, amenidad y los residenciales a provincias vecinas. Esta situación de saldo negativo desaparece desde 2009 para los extranjeros y el 2010 para los españoles. La crisis parece limitar las salidas a otras comunidades autónomas pero también 
es importante señalar la mejor situación económica de la región, lo que explicaría el aumento de la inmigración desde otras zonas del país (Tabla 4). Por lo que respecta al saldo exterior, antes positivo entre los españoles y los extranjeros, la crisis ha reducido las entradas y agudizado las salidas de extranjeros y españoles. En ambos saldos se observa un desfase cronológico en el cambio del signo del saldo por nacionalidad, que es anterior en ambos tipos de flujos en los españoles que en los extranjeros. Este desfase es mayor en el saldo exterior (3 años) y podría explicarse porque mientras que en los extranjeros las salidas se retrasarían hasta la finalización del período de cobertura del desempleo, en el caso de los españoles hay una bolsa importante de jóvenes que no han conseguido su primer empleo y que verían en la emigración al extranjero una solución inmediata a su difícil situación.

En segundo lugar, la mayor incidencia de la crisis en el colectivo de los extranjeros está disminuyendo el peso de los mismos en el total de migrantes. Si en los años anteriores a la crisis, los extranjeros llegaron a representar algo más de la mitad de los migrantes, con un máximo del 57,29\% en 2007, en 2013 solo representaron el 46,56\%, con valores que no alcanzan el 50 \% desde 2010. En 2013 los extranjeros son solo mayoritarios en la migración exterior representando ya el 30\% de los migrantes internos y el $25 \%$ de los interprovinciales, cuando en 2007 suponían el $35,12 \%$ y el $34,63 \%$ respectivamente. La caída del peso de los extranjeros se produce en todos los tipos de flujos pero tienen especial importancia en los flujos de mayor distancia como el exterior y el interprovincial.

Tabla 4. Saldos migratorios según tipo de flujo y nacionalidad. Comunidad de Madrid

\begin{tabular}{|r|r|r|r|r|r|r|r|r|r|}
\hline Años & $\begin{array}{c}\text { CCAA } \\
\text { Total }\end{array}$ & $\begin{array}{c}\text { CCAA } \\
\text { españoles }\end{array}$ & $\begin{array}{c}\text { CCAA } \\
\text { extranjeros }\end{array}$ & $\begin{array}{c}\text { Exterior } \\
\text { Total }\end{array}$ & $\begin{array}{c}\text { Exterior } \\
\text { Españoles }\end{array}$ & $\begin{array}{c}\text { Exterior } \\
\text { Extranjeros }\end{array}$ & $\begin{array}{c}\text { Saldo } \\
\text { Total }\end{array}$ & $\begin{array}{c}\text { Total } \\
\text { Españoles }\end{array}$ & $\begin{array}{c}\text { Total } \\
\text { Extranjeros }\end{array}$ \\
\hline 2003 & -27856 & -19365 & -8491 & 121353 & 2727 & 118625 & 93497 & -16638 & 110134 \\
\hline 2004 & -33331 & -22677 & -10654 & 111217 & 3811 & 107406 & 77886 & -18866 & 96752 \\
\hline 2005 & -29994 & -21758 & -8236 & 113589 & 4165 & 111424 & 83595 & -17593 & 103188 \\
\hline 2006 & -23542 & -17863 & -5679 & 137015 & 1769 & 135246 & 113473 & -16094 & 129567 \\
\hline 2007 & -16538 & -7770 & -8768 & 125165 & 550 & 124615 & 108627 & -7220 & 115847 \\
\hline 2008 & -10373 & -4170 & -6203 & 74192 & -1111 & 75303 & 63819 & -5281 & 69100 \\
\hline 2009 & -2200 & -1031 & -1169 & 31237 & -1530 & 32767 & 29037 & -2561 & 31598 \\
\hline 2010 & -1017 & 948 & -1965 & 4037 & -1202 & 5239 & 3020 & -254 & 3274 \\
\hline 2011 & 8377 & 11205 & -2828 & -19181 & -3947 & -15234 & -10804 & 7258 & -18062 \\
\hline 2012 & 15386 & 13564 & 1822 & -12434 & -5414 & -7020 & 2952 & 8150 & -5198 \\
\hline 2013 & 15003 & 11292 & 3711 & -36165 & -8729 & -27436 & -21162 & 2563 & -23725 \\
\hline
\end{tabular}

Fuente: elaboración propia a partir de Estadísticas del Movimiento Migratorio de la Comunidad de Madrid (IESTADIS, 2003-2013)

En tercer lugar, la crisis ha traído a la Comunidad de Madrid un nuevo modelo migratorio. Teniendo en cuenta los tres grandes grupos de migrantes (Tabla 5), antes de la crisis en la mayoría de los años del presente siglo nos encontramos con un predominio de los externos seguidos por los 
interprovinciales y en último lugar los interiores. Desde el año 2009 y como consecuencia del hundimiento de la inmigración del extranjero, predominan los interprovinciales seguidos, bien por los externos, bien por los internos según los años. Este modelo en 2013 es diferente al español por cuanto en ese año, en el país el flujo interior es el más elevado (39,5\% migrantes), seguido del exterior $(33,9 \%$ ) y el interprovincial $(26,6 \%)$. En definitiva, el modelo madrileño en 2013 presenta con respecto al país, un mayor peso de la migración interprovincial, que agrupa el mayor número de migrantes, un mayor peso de la interior y un valor casi similar en el caso de la migración exterior.

El análisis más concreto por tipos de flujos pone más de relieve el cambio acontecido (Tabla 2). Entre 2000 y 2007 la inmigración del extranjero fue el principal flujo migratorio de la Comunidad de Madrid en cinco años, situándose en tres por detrás de la migración interna. Pues bien, desde 2010 la inmigración del extranjero ocupa el último lugar entre los tipos de flujos, siendo superada por la migración interna, la inmigración y la emigración entre comunidades autónomas y la propia emigración al extranjero. Esta última se sitúa en 2013 como segundo flujo tras la migración interna, cuando hasta 2010 constituía el tipo de flujo más reducido, subrayándose la importancia de la crisis como factor determinante en el retorno de los extranjeros o de los españoles de origen extranjero (nacionalizados) y de la creciente salida de españoles ante la mala situación del mercado de trabajo.

Tabla 5. Migrantes según tipo de flujo. Comunidad de Madrid

\begin{tabular}{|r|r|r|r|}
\hline Años & \% Internos & \% Extranjero & \% CCAA \\
\hline 1998 & 48,13 & 7,23 & 44,64 \\
\hline 1999 & 43,59 & 13,43 & 42,67 \\
\hline 2000 & 29,08 & 41,37 & 29,56 \\
\hline 2001 & 29,15 & 40,53 & 30,32 \\
\hline 2002 & 31,17 & 35,34 & 33,48 \\
\hline 2003 & 32,45 & 31,04 & 36,52 \\
\hline 2004 & 33,19 & 28,98 & 37,84 \\
\hline 2005 & 32,90 & 29,51 & 37,59 \\
\hline 2006 & 30,37 & 34,93 & 34,70 \\
\hline 2007 & 27,27 & 37,96 & 34,77 \\
\hline 2008 & 28,07 & 36,17 & 35,76 \\
\hline 2009 & 32,29 & 29,35 & 38,36 \\
\hline 2010 & 32,65 & 29,03 & 38,33 \\
\hline 2011 & 29,72 & 33,47 & 36,81 \\
\hline 2012 & 30,73 & 30,71 & 38,56 \\
\hline 2013 & 29,91 & 33,59 & 36,50 \\
\hline
\end{tabular}

Fuente: elaboración propia a partir de Estadísticas del Movimiento Migratorio de la Comunidad de Madrid (IESTADIS, 1998-2013) 


\section{Las diferencias espaciales en la evolución e intensidad de la migración}

El análisis comparativo entre 2007 y 2013 en valores relativos de los migrantes permite constatar interesantes diferencias espaciales, tanto en la evolución de los flujos migratorios, como en la intensidad de los mismos antes y durante la crisis económica actual (Tabla 6).

En la inmigración la caída es fuerte y general, pero ha sido mayor en el conjunto de municipios periurbanos muy afectados por la crisis inmobiliaria (paralización de la construcción y venta de viviendas y de la industria asociada), seguidos de la corona metropolitana y en especial de su área este (Corredor del Henares) y sur, las más afectadas por la crisis por su estructura productiva y la debilidad de su mercado laboral y mucho más reducida en la Capital. En los tres grandes ámbitos, el descenso se debe sobre todo a la caída de la inmigración extranjera, pero también lo hace por el descenso de la procedente de otras comunidades autónomas, y en mayor medida por la caída de la inmigración interna por la ralentización del proceso de suburbanización. Solo en este último tipo de inmigración se produce la excepción de Madrid, donde se observa un aumento explicable por una combinación de motivos laborales y residenciales. Entre los primeros, se puede señalar el retorno de antiguos emigrantes internos españoles y extranjeros desde ámbitos metropolitanos y sobre todo periurbanos, más afectados por la crisis y la creciente llegada de nuevos inmigrantes por las mayores posibilidades de empleo en la Capital. Entre los residenciales cabe mencionar la presencia de inmigrantes atraídos por la gran oferta de vivienda nueva en los desarrollos de la nueva periferia madrileña o a la generada en el centro y periferia consolidada de la ciudad asociada en unos casos a la rehabilitación y renovación residencial y en otros a la creciente "liberación" de vivienda en relación con el proceso de envejecimiento demográfico que favorece la salida de un creciente stock inmobiliario al mercado y la progresiva sustitución de la población (López Gay, 2011).

En la emigración el descenso es menor y es la corona metropolitana, con las áreas este y sur a la cabeza de nuevo, la que sufre los descensos mayores seguida por la Capital; descenso que en todos los casos se debe al frenazo de la emigración interna y hacia otras regiones, ya que la emigración al extranjero aumenta de forma muy importante. A diferencia de la inmigración, el descenso no es general, ya que todas las coronas periurbanas han visto aumentar la emigración al sumarse a la exterior la interior. Este aumento de la emigración interior con destino al ámbito metropolitano se vincula a una mayor incidencia de la crisis en el espacio periurbano, relacionada con una estructura productiva con un mayor peso de la construcción y una mayor facilidad de destrucción de empleo, dada la juventud de su población y la temporalidad del mercado de trabajo. 
Tabla 6. Evolución inmigrantes y emigrantes

por tipos de flujos en la Comunidad de Madrid (2007-2013)

\begin{tabular}{|c|c|c|c|c|c|c|c|c|}
\hline Inmigrantes & Total & Interior & CCAA & Exterior & Total \% & Interior \% & CCAA \% & Exterior \% \\
\hline Madrid & $\mid-57714$ & 2043 & -2684 & -57073 & $-30,49$ & 5,71 & $-4,84$ & $-58,23$ \\
\hline AM Este & \begin{tabular}{|l|}
-19986 \\
\end{tabular} & -3988 & -584 & -15414 & $-42,89$ & $-20,32$ & $-7,45$ & $-80,55$ \\
\hline AM Norte & -4311 & -35 & 111 & -4387 & $-20,03$ & $-0,33$ & 3,13 & $-59,12$ \\
\hline AM Sur & -24477 & -7293 & 446 & -17630 & $-32,80$ & $-20,09$ & 3,11 & $-73,46$ \\
\hline AM Oeste & -8001 & -2253 & -461 & -5287 & $-28,59$ & $-15,12$ & $-10,17$ & $-61,84$ \\
\hline C. Metropolitana & -56775 & -13569 & -488 & -42718 & $-33,25$ & $-16,67$ & $-1,61$ & $-72,27$ \\
\hline $1^{\circ} \mathrm{C}$. periurbana & -16258 & -7331 & -205 & -8722 & $-36,48$ & $-27,66$ & $-3,11$ & $-75,99$ \\
\hline $2^{\mathrm{a} C}$. periurbana & -8125 & -3456 & -373 & -4296 & $-33,90$ & $-23,33$ & $-10,86$ & $-75,12$ \\
\hline $3^{\mathrm{a} C} \mathrm{C}$. periurbana & -5244 & -2072 & -97 & -3075 & $-39,67$ & $-29,98$ & $-3,88$ & $-80,79$ \\
\hline $4^{\mathrm{a} C}$. periurbana & -1507 & -234 & -21 & -1252 & $-30,94$ & $-8,60$ & $-3,21$ & $-83,75$ \\
\hline Total Periurbano & -31134 & -13093 & -696 & -17345 & $-35,94$ & $-25,70$ & $-5,28$ & $-77,10$ \\
\hline Emigrantes & Total & Interior & CCAA & Exterior & Total \% & Interior \% & CCAA \% & Exterior \% \\
\hline Madrid & -8089 & -18163 & -19212 & 29286 & $-5,06$ & $-29,05$ & $-32,69$ & 76,01 \\
\hline AM Este & -4859 & -2139 & -4559 & 1839 & $-15,39$ & $-12,92$ & $-39,10$ & 54,98 \\
\hline AM Norte & -325 & -1144 & -660 & 1479 & $-1,99$ & $-10,94$ & $-17,64$ & 68,73 \\
\hline AM Sur & -7212 & -4204 & -7376 & 4368 & $-11,99$ & $-12,46$ & $-34,48$ & 86,86 \\
\hline AM Oeste & -1497 & -1896 & -960 & 1359 & $-7,17$ & $-13,60$ & $-21,33$ & 56,20 \\
\hline C. Metropolitana & -13893 & -9383 & -13555 & 9045 & $-10,77$ & $-12,56$ & $-32,82$ & 69,88 \\
\hline $1^{\mathrm{a} C}$. periurbana & 3405 & 1331 & -1314 & 3388 & 13,89 & 8,81 & $-16,95$ & 204,10 \\
\hline $2^{\mathrm{a} C}$. periurbana & 1451 & 896 & -734 & 1289 & 10,20 & 9,52 & $-17,93$ & 179,53 \\
\hline $3^{\mathrm{a}} \mathrm{C}$. periurbana & 942 & 467 & -426 & 901 & 12,98 & 11,01 & $-16,53$ & 206,65 \\
\hline $4^{\mathrm{a} C}$. periurbana & 350 & 233 & -168 & 285 & 10,89 & 11,07 & $-17,63$ & 183,87 \\
\hline Total Periurbano & 6148 & 2927 & -2642 & 5863 & 12,49 & 9,48 & $-17,18$ & 197,47 \\
\hline
\end{tabular}

Fuente: elaboración propia a partir de Estadísticas del Movimiento Migratorio de la Comunidad de Madrid (IESTADIS, 2007-2013)

El análisis de las tasas de inmigración, emigración y migración neta de 2007 y 2013 (Tabla 7) constata el mantenimiento a nivel comarcal de las mismas diferencias espaciales, eso sí, con valores mucho más reducidos en 2013, pudiéndose destacar los aspectos siguientes:

- Hay una disminución de las diferencias territoriales en la inmigración, la emigración y la migración neta, ya que las mayores y menores caídas se corresponden con las tasas más altas y bajas en 2007.

- En la inmigración y la emigración los valores más altos se corresponden con los municipios periurbanos y los más bajos con la Capital, con la corona metropolitana en un lugar intermedio. 
- Dentro de la corona metropolitana las áreas norte y oeste tienen los valores más altos en la inmigración, la emigración y la migración neta, mientras que las sur y este tienen los valores más bajos. Esta oposición intrametropolitana (norte y oeste frente a sur y este) se produce ya antes de la crisis, pero se agudiza con ella, y subraya el contraste entre la zona de mayor dinamismo económico, crecimiento residencial, nivel socioeconómico de la población y menor incidencia de la crisis, con la más afectada por la misma por su baja cualificación socioprofesional, escaso nivel socioeconómico y estructura productiva con mayor peso de sectores débiles en la crisis (construcción e industria asociada, comercio, hostelería, servicios personales...).

- En el conjunto de municipios periurbanos el mayor protagonismo que tenía la $1^{a}$ corona en la inmigración en 2007, la más próxima a la corona metropolitana, deja paso en 2013 a la aparición de valores más altos en la $2^{a}$ corona en consonancia con la progresiva periferización del crecimiento relacionado con la continua expansión metropolitana madrileña. En el caso de la emigración, la crisis ha venido a igualar las tasas de las coronas periurbanas en contraste con la situación de 2007 cuando el protagonismo de la corona más alejada de la Comunidad de Madrid era muy notable.

- La situación de 2013 contrasta con la de 2007 en la migración neta por la presencia de valores negativos en la Capital, en la corona metropolitana, donde aparecen en las áreas este y sur que son los más afectados por la crisis, y en las coronas periurbanas más alejadas ( $3^{a}$ y $4^{a}$ corona) del conjunto de los municipios metropolitanos. La fuerte caída de la inmigración exterior en todos los ámbitos espaciales y de la interior en la corona metropolitana y municipios periurbanos que frena el proceso de suburbanización residencial, es el factor fundamental que provoca la presencia de tasas de migración neta negativas o muy escasamente positivas.

Tabla 7. Tasas de inmigración, emigración y migración neta por mil.

\section{Comunidad de Madrid}

\begin{tabular}{|l|r|r|r|r|r|r|}
\hline & TI 2007 & TE 2007 & TMN 2007 & TI 2013 & TE 2013 & TMN 2013 \\
\hline Madrid & 60,41 & 51,02 & 9,39 & 41,02 & 47,31 & $-6,30$ \\
\hline AM Este & 86,53 & 58,62 & 27,91 & 44,67 & 44,83 & $-0,16$ \\
\hline AM Norte & 84,08 & 63,88 & 20,2 & 60,79 & 56,61 & 4,18 \\
\hline AM Sur & 71,32 & 57,48 & 13,84 & 45,36 & 47,88 & $-2,52$ \\
\hline AM Oeste & 85,42 & 63,69 & 21,73 & 54,49 & 52,81 & 1,68 \\
\hline C. Metropolitana & 78,73 & 59,46 & 19,27 & 48,47 & 48,93 & $-0,46$ \\
\hline${\text { 1 }{ }^{\circ} \text { C. periurbana }}^{2}$ & 115,06 & 63,31 & 51,75 & 59,93 & 59,13 & 0,80 \\
\hline${\text { 2 }{ }^{\circ} \text { C. periurbana }}^{109,53}$ & 65,01 & 44,52 & 64,15 & 63,47 & 0,68 \\
\hline
\end{tabular}


Tabla 7. Continuación

\begin{tabular}{|l|r|r|r|r|r|r|}
\hline & TI 2007 & TE 2007 & TMN 2007 & TI 2013 & TE 2013 & TMN 2013 \\
\hline $3^{\text {a } C . ~ p e r i u r b a n a ~}$ & 100,89 & 55,37 & 45,52 & 49,63 & 51,02 & $-1,38$ \\
\hline $4^{\circ}$ C. periurbana & 111,66 & 73,65 & 38,01 & 59,10 & 62,60 & $-3,50$ \\
\hline Total Periurbano & 110,94 & 63,03 & 47,91 & 59,23 & 59,09 & 0,13 \\
\hline Comu. de Madrid & 73,44 & 55,58 & 17,86 & 46,34 & 49,60 & $-3,26$ \\
\hline
\end{tabular}

Fuente: elaboración propia a partir de Estadísticas del Movimiento Migratorio de la Comunidad de Madrid (IESTADIS, 2007 y 2013)

- El análisis de los saldos migratorios por tipos de flujos muestra dos momentos diferentes (Tabla 8). Antes de la crisis el saldo total positivo era general y muy elevado como consecuencia de un saldo externo que recogía la llegada masiva de extranjeros. Ese saldo externo compensaba en la Capital la presencia de saldos interprovinciales y sobre todo internos negativos. En la corona metropolitana y el espacio periurbano el saldo migratorio interno también era positivo, pero el saldo interprovincial era negativo. Con la crisis se generalizan los saldos negativos fruto de un saldo con el extranjero que es negativo en todos los ámbitos y de la disminución de los saldos internos en consonancia con la menor intensidad del proceso de suburbanización, apareciendo como gran novedad saldos positivos con el resto de las provincias, en la Capital y la corona metropolitana, al reducirse mucho la emigración por diversos factores y en cambio producirse un descenso escaso de la inmigración.

Tabla 8. Saldos migratorios según tipo de flujos. Comunidad de Madrid

\begin{tabular}{|l|r|r|r|r|r|r|r|r|}
\hline & \multicolumn{4}{|c|}{2007} & \multicolumn{3}{|c|}{2013} \\
\hline & Total & Exterior & CCAA & Interior & Total & Exterior & CCAA & Interior \\
\hline Madrid & 29422 & 59475 & -3281 & -26772 & -20203 & -26884 & 13247 & -6566 \\
\hline AM Este & 15030 & 15790 & -3824 & 3064 & -97 & -1463 & 151 & 1215 \\
\hline AM Norte & 5170 & 5268 & -201 & 103 & 1184 & -598 & 570 & 1212 \\
\hline AM Sur & 14478 & 18972 & -7060 & 2566 & -2141 & -3026 & 762 & 123 \\
\hline AM Oeste & 7119 & 6131 & 31 & 957 & 615 & -515 & 530 & 600 \\
\hline C. Metropolitana & 41797 & 46161 & -11054 & 6690 & -439 & -5602 & 2013 & 3150 \\
\hline $1^{\text {a }}$ C. periurbana & 20042 & 9818 & -1171 & 11395 & 379 & -2292 & -62 & 2733 \\
\hline $2^{\text {a }}$ C. periurbana & 9744 & 5001 & -659 & 5402 & 168 & -584 & -298 & 1050 \\
\hline $3^{\text {a } \text { C. periurbana }}$ & 5964 & 3370 & -75 & 2669 & -222 & -606 & 254 & 130 \\
\hline $4^{\text {a }}$ C. periurbana & 1658 & 1340 & -298 & 616 & -199 & -197 & -151 & 149 \\
\hline Total periurbano & 37408 & 19529 & -2203 & 20082 & 126 & -3679 & -257 & 4062 \\
\hline
\end{tabular}

Fuente: elaboración propia a partir de Estadísticas del Movimiento Migratorio de la Comunidad de Madrid (IESTADIS, 2007 y 2013) 
En definitiva, la crisis está detrás de tres procesos. Uno, de frenazo de la inmigración desde el extranjero y de aumento de la expulsión de españoles y extranjeros ante las dificultades de empleo que hunde el saldo migratorio exterior. Un segundo proceso de ralentización del papel redistribuidor de población (española y extranjera) en la Comunidad de Madrid, de la Capital y la corona metropolitana que frena además el tradicional proceso de suburbanización y expansión periférica metropolitana en el espacio periurbano. Por último, una revitalización de los saldos interprovinciales en el Área Metropolitana, que se debe a una caída grande de la emigración relacionada con tres hechos: la disminución de la migración residencial a las provincias vecinas de Toledo y Guadalajara, el menor papel redistribuidor de extranjeros hacia el resto del país por el hundimiento de la inmigración desde el extranjero y por último, los efectos de la propia crisis en una menor movilidad de los extranjeros residentes y la disminución de flujos emigratorios de retorno, ocio o de carácter laboral a otras áreas del país. Esta caída de la emigración contrasta con una disminución escasa de la inmigración en relación con la mejor situación económica y laboral del Área Metropolitana madrileña con respecto a otros territorios del país.

La combinación de esos tres procesos provoca que el modelo migratorio presente una mayor homogeneidad espacial en la actualidad que antes de la crisis. En 2007 el reparto de los migrantes entre flujo interno, interprovincial y exterior permitía diferenciar entre tres modelos: el de la Capital, de predominio de la migración externa seguida de la interprovincial; el de la corona metropolitana, de predominio de la migración interna seguida de la exterior, y el del conjunto periurbano, de predominio de nuevo del flujo interno seguido del interprovincial. En 2013 solo hay dos modelos, el de Madrid, similar al de 2007, y el del resto de ámbitos de predominio de la migración interna seguida de la interprovincial (Tabla 9).

La escala municipal permite ahondar en el conocimiento de las diferencias espaciales en la intensidad tanto de la inmigración como de la emigración y la migración neta.

Por lo que respecta a la inmigración (Figura 4) la caída de la tasa es general. En 2005-2007 con valores muy contrastados, había nada menos que 97 municipios con tasas por encima del $100 \%$ y tan solo 3 municipios con menos del 50 \%. En 2011-2013 el abanico de valores se reduce y tan solo 10 municipios superaban la barrera del $100 \%$ y 47 no llegaban al $50 \%$. En cuanto a las pautas espaciales, si en 2007 las mayores tasas (más del $75 \%$ ) se extendían de forma generalizada y en todas las direcciones por las coronas periurbanas y los municipios de las áreas oeste y este y parte del sur y norte metropolitano, en 2013 desaparecen las altas tasas de los cuatro sectores metropolitanos, quedando constreñidas al espacio periurbano con una limitación espacial evidente en todas las direcciones y una mayor presencia en el noreste, este y oeste periurbano de la región. En contraste, los valores más bajos se encuentran en la Capital y sur metropolitano, como 
en 2007, a los que se añade en 2013 el este metropolitano, el sureste periurbano y parte de los pequeños municipios serrano limítrofes.

Tabla 9. Reparto de los migrantes por grandes flujos en la comunidad de Madrid

\begin{tabular}{|l|r|r|r|r|r|r|}
\cline { 2 - 7 } \multicolumn{1}{c|}{} & \multicolumn{3}{c|}{ Migrantes 2007 } & \multicolumn{3}{c|}{ Migrantes 2013} \\
\hline & Interior \% & CCAA \% & Exterior \% & Interior \% & CCAA \% & Exterior \% \\
\hline Madrid & 28,16 & 32,73 & 39,11 & 29,01 & 32,61 & 38,39 \\
\hline AM Este & 46,29 & 24,94 & 28,76 & 56,38 & 26,92 & 16,70 \\
\hline AM Norte & 55,50 & 19,23 & 25,27 & 59,69 & 20,26 & 20,05 \\
\hline AM Sur & 51,96 & 21,54 & 26,50 & 56,78 & 27,93 & 15,29 \\
\hline AM Oeste & 59,06 & 18,49 & 22,45 & 62,77 & 19,34 & 17,89 \\
\hline C. Metropolitana. & 52,09 & 23,87 & 24,04 & 58,14 & 25,11 & 16,76 \\
\hline $1^{\circ}$ C. periurbana & 60,23 & 20,75 & 19,02 & 63,33 & 22,79 & 13,88 \\
\hline $2^{\circ}$ C. periurbana & 63,43 & 19,71 & 16,85 & 68,74 & 20,37 & 10,88 \\
\hline $3^{\circ}$ C. periurbana & 54,47 & 24,81 & 20,72 & 59,04 & 28,17 & 12,79 \\
\hline $4^{\circ}$ C. periurbana & 59,70 & 20,41 & 19,89 & 69,65 & 20,49 & 9,86 \\
\hline Total Periurbano & 60,23 & 21,02 & 18,75 & 64,64 & 22,75 & 12,62 \\
\hline
\end{tabular}

Fuente: elaboración propia a partir de Estadísticas del Movimiento Migratorio de la Comunidad de Madrid (IESTADIS, 2007 y 2013)

Figura 4. Tasas de inmigración 2005-2007 y 2011-2013

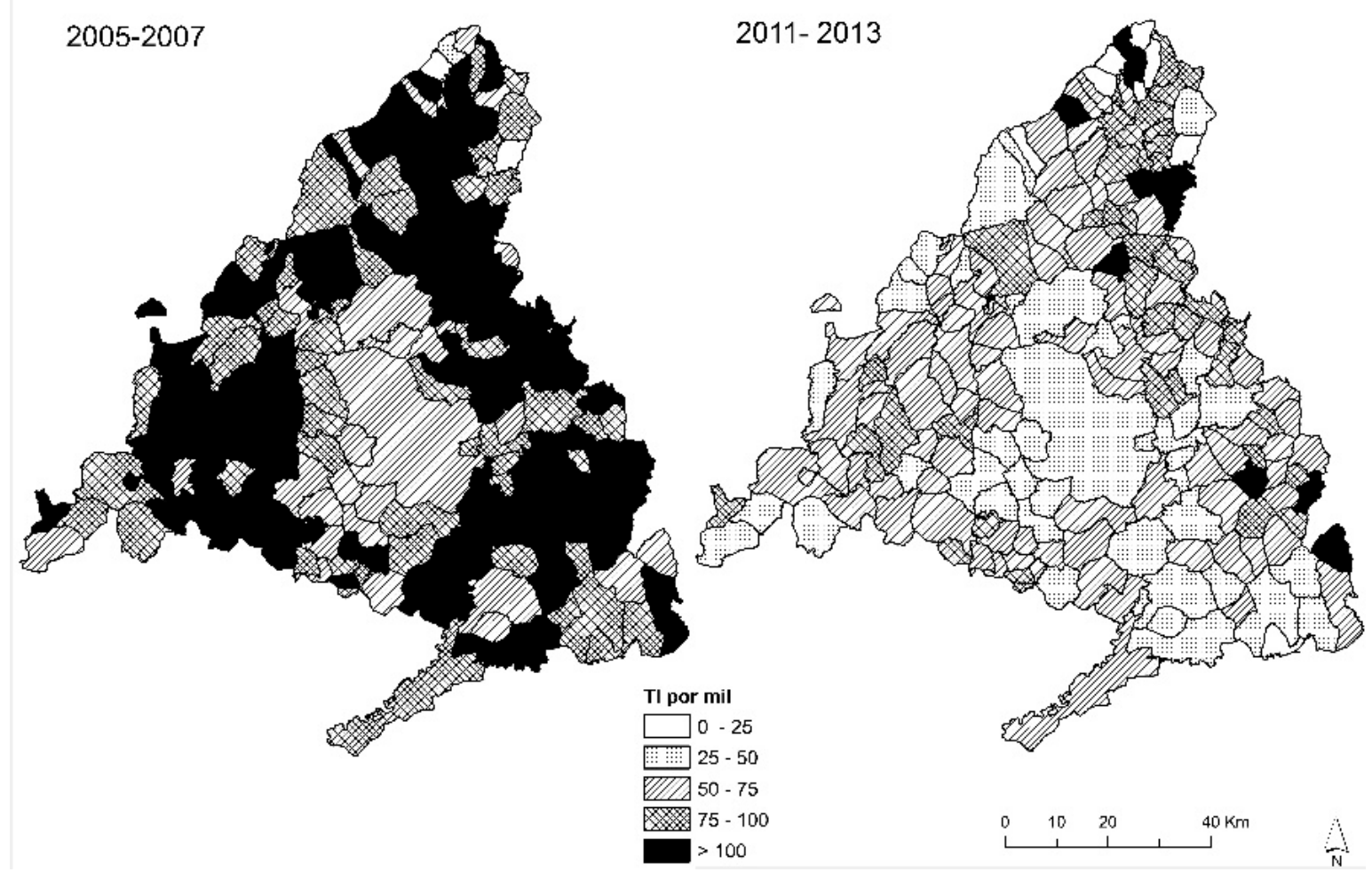

Fuente: elaboración propia a partir de Estadísticas del Movimiento Migratorio de la Comunidad de Madrid (IESTADIS, 2005-2007 y 2011-2013) 
En la emigración (Figura 5) la caída de la tasa es menos general pues hay 63 municipios periurbanos donde aumenta entre los dos períodos, disminuyendo en la mayoría de los municipios metropolitanos. En ambos años el abanico de valores es más reducido y hay una mayor homogeneidad en las tasas, apareciendo los valores más altos en los municipios del norte, oeste y el este de la región y los más bajos en el ámbito metropolitano y sureste de la Comunidad.

\section{Figura 5. Tasas de emigración 2005-2007 y 2011-2013}

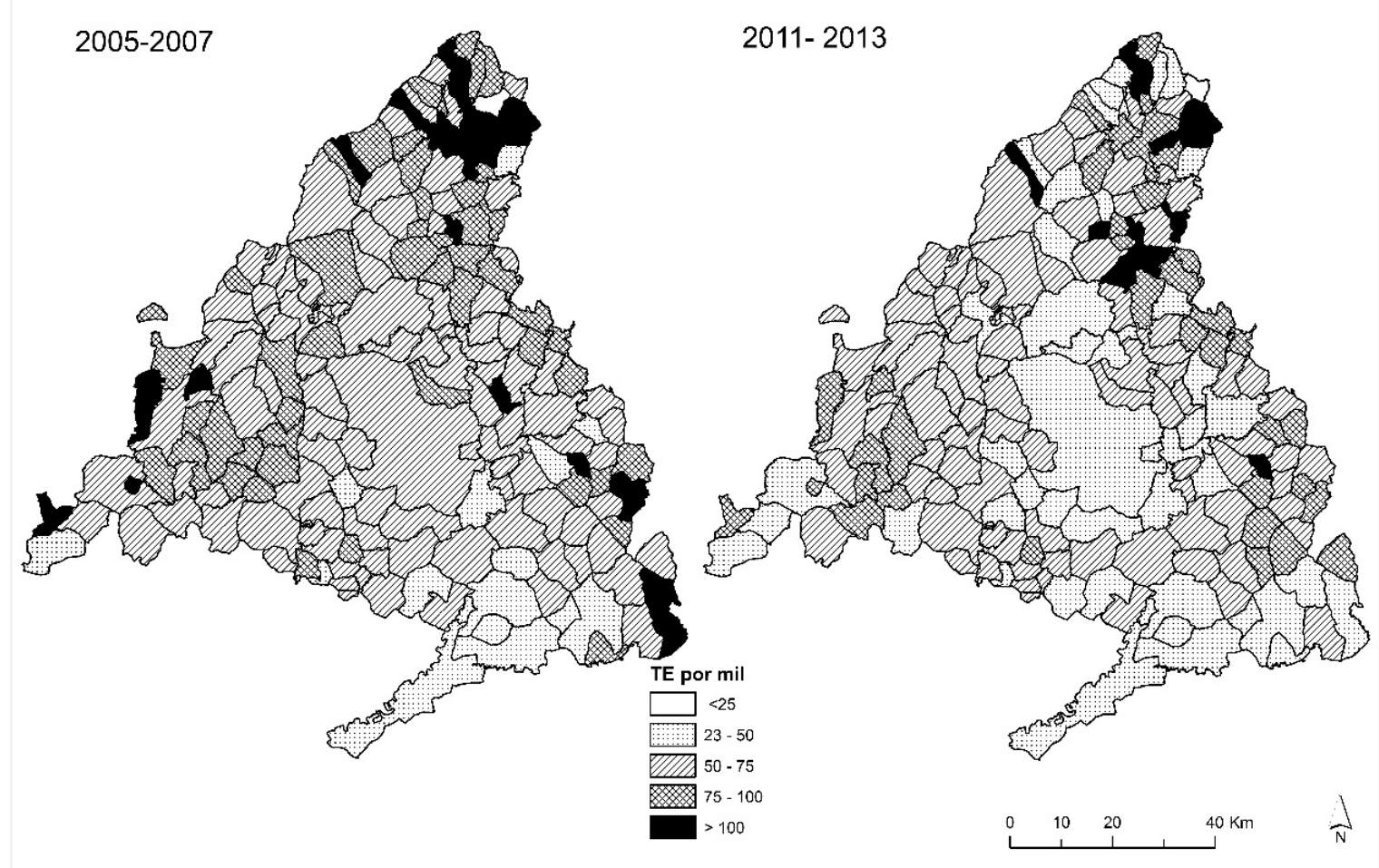

Fuente: elaboración propia a partir de Estadísticas del Movimiento Migratorio de la Comunidad de Madrid (IESTADIS, 2005-2007 y 2011-2013)

Las tasas de migración neta (Figura 6) reflejan muy bien el cambio acaecido entre los dos períodos. En el primero, las tasas eran negativas en 16 municipios pequeños ubicados en su mayoría en el norte montañoso, alejados de la influencia del proceso de expansión metropolitana y poco atractivos a los crecientes flujos migratorios ciudad-campo. En contraste, otros 59 municipios presentan tasas muy elevadas (más del $50 \%$ ), con una localización periurbana y en todas las direcciones (solo hay 3 municipios metropolitanos), poniendo de manifiesto el espectacular proceso de expansión de la urbanización metropolitana en ese ámbito. En 2011-2013 la situación es distinta. Por un lado, aumentan a 91 los municipios con tasas negativas, que se extienden por el ámbito metropolitano, sobre todo por sus sectores sur y este y la Capital, y también por el periurbano con especial presencia en el sureste, suroeste y municipios serranos limítrofes de la región, a causa de la menor entrada de extranjeros, del retorno a sus países o de la salida a otros ámbitos de personas por la crisis. Por otro lado, se reducen los municipios con tasas positivas, 
presentando una mayor homogeneidad en valores reducidos y una distribución espacial en la que se observa la convivencia de municipios metropolitanos del norte y oeste, los ámbitos más dinámicos, y de municipios periurbanos en todas las direcciones pero coincidentes en muchos casos con áreas donde se mantiene un cierto dinamismo residencial y la llegada de inmigrantes (márgenes Corredor del Henares al este, La Sagra al sur, eje viario de la A-1 al norte y oeste periurbano).

Figura 6. Tasas de migración neta 2005-2007 y 2011-2013

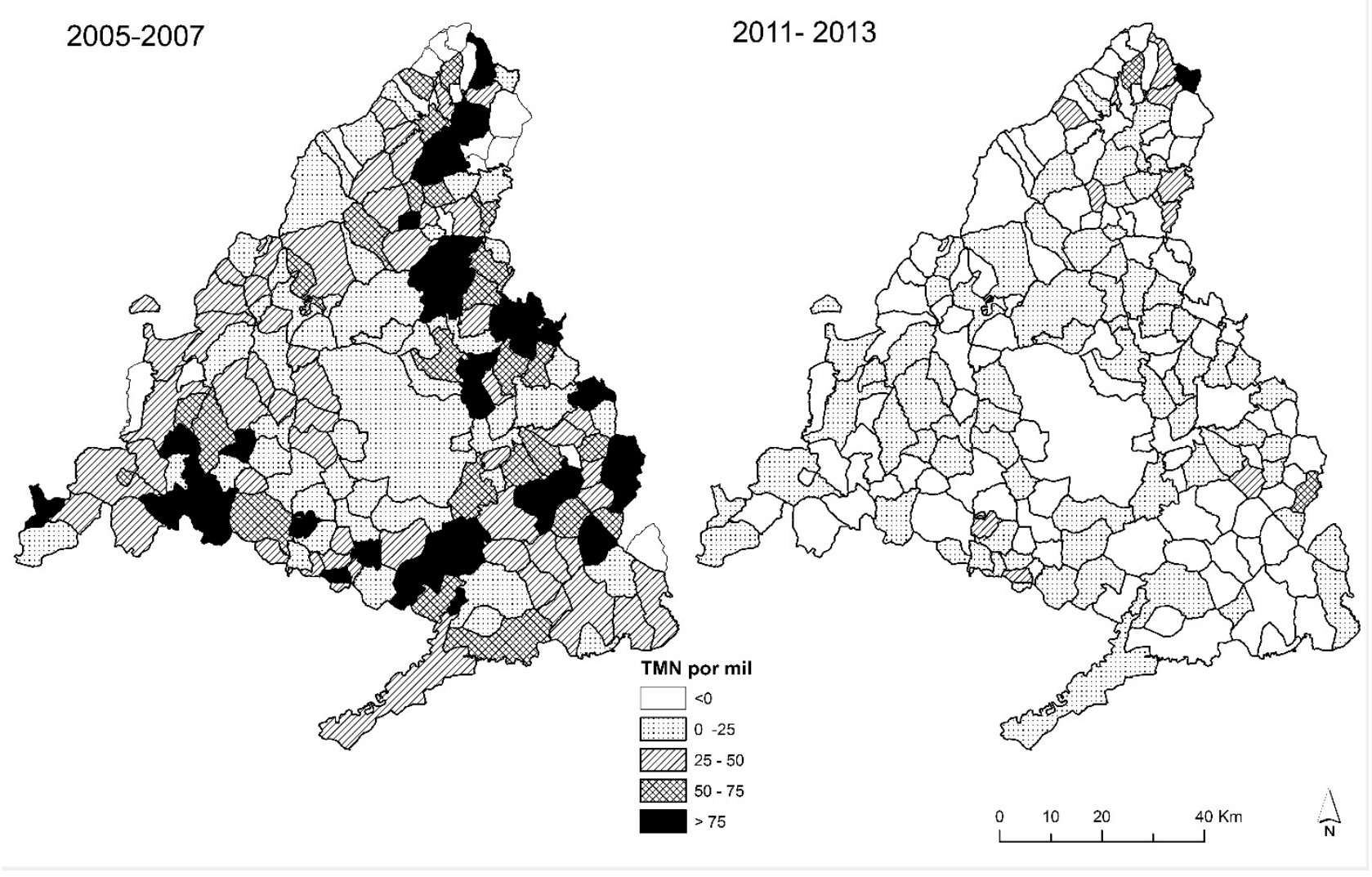

Fuente: elaboración propia a partir de Estadísticas del Movimiento Migratorio de la Comunidad de Madrid (IESTADIS, 2005-2007 y 2011-2013)

\section{Conclusiones}

Con la crisis económica se ha producido un cambio en el modelo demográfico de la Comunidad de Madrid. De una situación previa de fuerte crecimiento por la inmigración exterior, generalizada además en la mayoría de los ámbitos comarcales y de los municipios, se ha pasado a una etapa de lento crecimiento condicionada por la presencia de un saldo migratorio menor. Este cambio ha provocado la reaparición de dinámicas de decrecimiento en un gran número de municipios, incluida la Capital, prácticamente inexistentes antes de la crisis.

La crisis está detrás de la caída del número de migrantes y de la tasa de migración bruta. Por grandes conjuntos de flujos es mayor en la migración exterior y menor en la interprovincial y la 
interior. Si distinguimos entre inmigración y emigración se observa el fuerte aumento de las salidas al extranjero y en las dinámicas de descenso una caída mayor en la inmigración desde el exterior seguida de la emigración a otras provincias y otra menor en la inmigración desde otras provincias

El viejo modelo migratorio precrisis definido por el papel dominante de la migración exterior y la presencia de un saldo migratorio regional positivo, deja paso a otro de predomino de la migración interior o de la interprovincial según el año de análisis, y a un saldo migratorio regional negativo.

Además de la existencia de un saldo migratorio exterior negativo fruto de la caída importante de la inmigración extranjera y el aumento de la emigración, se ha producido un cambio en el saldo interprovincial que ha pasado de ser negativo a positivo tanto en los extranjeros como en los españoles. Mientras que en los primeros la causa es la reducción de la emigración, por el menor papel redistribuidor de migrantes extranjeros, en relación con la caída de inmigrantes desde el exterior, en los españoles se observa un aumento de la inmigración y un descenso de la emigración a otras provincias que engloba fenómenos diversos como la reducción de la migración residencial a las provincias vecinas, o la mejor situación económica de la región en comparación con otras zonas del país que alimentaría un doble proceso de aumento de la atracción y disminución de la expulsión de la región en los flujos laborales, y la disminución de flujos de ocio y de retorno.

El análisis territorial de la inmigración y la emigración descubre diferencias comarcales y municipales en dos cuestiones. En primer lugar, en el ritmo de descenso de migrantes. Así en la inmigración, con una caída en general fuerte, el descenso es mayor en las coronas periurbanas seguida de la corona metropolitana y en todos los tipos de flujos, mientras que en la Capital es menor y con un aumento de inmigrantes internos. En la emigración el descenso es menor con la caída más baja en la Capital y la más alta en la corona metropolitana. En segundo lugar, en los valores de las tasas que son mayores en las coronas periurbanas seguidas de la corona metropolitana y la Capital. Las diferencias son similares antes y en la crisis pero se observa una mayor homogeneidad en los valores en la actualidad que es mayor en la emigración que en la inmigración.

La mayor caída de la inmigración y la menor de la emigración hacen aparecer comarcas y municipios con tasas de migración neta negativas. Esta situación, mínima antes de la crisis, aparece en la Capital, en municipios del sur y este metropolitano, y en muchos de las coronas periurbanas ubicados sobre todo en las más alejadas al Área Metropolitana. En la etapa precrisis la fuerte y generalizada entrada de extranjeros explicaba un alto saldo migratorio exterior que además de ser el principal en la mayoría de municipios, compensaba la presencia de saldos migratorios interprovinciales e internos negativos en muchos municipios metropolitanos y los más alejados del ámbito periurbano. En la crisis la inversión del saldo exterior lo convierte en el factor determinante de la aparición de tasas negativas. Así mismo su viejo papel predominante deja paso a una situación de predominio del saldo interno e interprovincial en el conjunto del saldo migratorio. 
Agradecimientos: El presente artículo se ha realizado con la financiación del Grupo de investigación SocialBigdata-CM (H2015/HUM-3427).

Declaración responsable: Las/os autoras/es declaran que no existe ningún conflicto de interés en relación a la publicación de este artículo. Asimismo, las/os dos autoras/es declaran que han elaborado conjuntamente todos los apartados del artículo. 


\section{Bibliografía}

Aja, E., Arango, J., \& Oliver, J. (2009). La inmigración en tiempos de crisis. Anuario de Inmigración en España. CIDOB.

Aja, E., Arango, J., \& Oliver, J. (2013). Anuario de Inmigración en España. CIDOB.

Gil-Alonso, F; Bayona, J., \& Pujadas, I. (2016). From boom to crash: Spanish urban areas in a decade of changes (2001-2011). European Urban and Regional Studies, 23(2), 198-216.

Bayona, J., \& Pujadas, I. (2014). Movilidad residencial y redistribución de la población metropolitana: los casos de Madrid y Barcelona. Eure, 40(119), 261-287.

Dominguez-Mujica, J. (2013). La huella de la crisis económica en la demografía y sociedad españolas: más interrogantes que certezas. Paper presented at the Congreso Territorios ante la crisis. ¿Territorios en crisis? Barcelona, Universitat de Barcelona. Retrieved from https://acceda.ulpgc.es/bitstream/10553/12856/2/0707223_00000_0000.pdf

Domínguez-Mujica, J., Guerra, R., \& Parreño, J. (2014). Migration at a Time of Global Economic Crisis: The Situation in Spain. International Migration, 52, 113-127.

Domingo, A., \& Recaño, J. (2010). La inflexión del ciclo migratorio internacional in España. Impacto y consecuencias demográficas. In E. Aja, J. Arango, \& J. Oliver (Eds.), La inmigración en tiempos de crisis. Anuario de la inmigración en España (pp. 182-207). Barcelona: CIDOB.

Feria Toribio, J. M. (2010). La delimitación y organización espacial de las áreas metropolitanas: una perspectiva desde la movilidad residencia-trabajo. Ciudad y Territorio, XLII(164), 189-210.

Ganau, J., \& Porsche, C. (2014). De nuevo emigrantes. Las nuevas dinámicas de emigración de la población española y la formación de un mercado laboral europeo (2008-2014). In A. López Gay, F. Rojo, M. Solsona, A. Andújar, J. Cruz, R. Iglesias, J. M. Feria, \& A. Vahí (Eds.), Cambio demográfico y socio territorial en un contexto de crisis (pp. 352-364). Sevilla: Grupo de Población de la Asociación de Geógrafos Españoles.

García, A., \& Pumares, P. (2014). Crisis y movilidad geográfica de los jóvenes en España. In A. López Gay, F. Rojo, M. Solsona, A. Andújar, J. Cruz, R. Iglesias, J. M. Feria, \& A. Vahí (Eds.), Cambio demográfico y socio territorial en un contexto de crisis (pp. 406-419). Sevilla: Grupo de Población de la Asociación de Geógrafos Españoles.

García-Palomares, J. C., \& Pozo, E. (2010). Movimientos migratorios en la Comunidad de Madrid: unos flujos más intensos y complejos (1991-2006). Boletín de la Asociación de Geógrafos Españoles, 53, 89-119. 
Gil-Alonso, F., Bayona, J., \& Pujadas, I (2015). Las migraciones internas de los extranjeros en España: dinámicas espaciales recientes bajo el impacto de la crisis. Boletín de la Asociación de Geógrafos Españoles, 69, 233-261.

González-Ferrer, A. (2013). La nueva emigración española. Lo que sabemos y lo que no. Zoom Político, 18, 1-20. Retrieved from

http://backend.demografia.ieg.csic.es/upload/files/cv/pdf/publication/192162489371182436 626209059180.pdf

Gutiérrez, A., \& Delclòs, X. (2014). Migraciones residenciales en Cataluña (2003-2012) ¿Cambios de pautas a partir de la crisis económica? In A. López Gay, F. Rojo, M. Solsona, A. Andújar, J. Cruz, R. Iglesias, J. M. Feria, \& A. Vahí (Eds.), Cambio demográfico y socio territorial en un contexto de crisis (pp. 571-584). Sevilla: Grupo de Población de la Asociación de Geógrafos Españoles.

IESTADIS (Instituto de Estadística de la Comunidad de Madrid) (1996-2014). Estadísticas del movimiento Migratorio de la Comunidad de Madrid. Retrieved from http://www.madrid.org/iestadis/fijas/estructu/demograficas/migra/estructumigra.htm

IESTADIS (Instituto de Estadística de la Comunidad de Madrid) (1996-2014). Padrón Anual de Habitantes de la Comunidad de Madrid. Retrieved from http://www.madrid.org/iestadis/fijas/estructu/demograficas/padron/estructupcrd.htm

IESTADIS (Instituto de Estadística de la Comunidad de Madrid) (1996-2013). Movimiento Natural de la Población de la Comunidad de Madrid. Retrieved from http://www.madrid.org/iestadis/fijas/estructu/demograficas/mnp/estructu_mnp.htm

López Gay, A. (2011). «¿Vuelve el centro? Caracterización demográfica de los procesos de reurbanización en las metrópolis españolas. In I. Pujadas et al. (Eds.), Población y Espacios urbanos (pp. 163-180). Barcelona: UB y Grupo de Población de la Asociación de Geógrafos Españoles.

Méndez, R., Abad, L., \& Echanoves, C. (2015). Atlas de la crisis. Impactos socioeconómicos y territorios vulnerables en España. Valencia: Tirant lo Blanch.

Ministerio de la Vivienda (2007). Atlas estadístico de las áreas urbanas. Madrid: Ministerio de la Vivienda.

Pozo, E., \& García, J. C. (2009). Inmigración y cambio demográfico en la región metropolitana madrileña. Anales de Geografía de la Universidad Complutense, 29(1), 113-140.

Pozo, E. \& García, J. C. (2011). Evolución reciente y pautas de distribución espacial de las migraciones internas de extranjeros: el caso de la Comunidad de Madrid (1997-2008). Scripta Nova, XV(384). Retrieved from http://www.ub.es/geocrit/sn/sn-384.htm 
Pozo, E., Rodríguez, J. Ma, \& García, J. C. (2012). La expansión metropolitana en los municipios de la franja toledana-madrileña (2000-2010). In Actas del XIII Congreso de la Población Española (pp. 136-144).

Pujadas I., Bayona, J., \& Gil-Alonso, F. (2004). Pautas territoriales recientes de la movilidad residencial en las mayores regiones metropolitanas españolas: ¿Cambios coyunturales 0 estructurales? In A. López Gay, F. Rojo, M. Solsona, A. Andújar, J. Cruz, R. Iglesias, J. M. Feria, \& A. Vahí (Eds.), Cambio demográfico y socio territorial en un contexto de crisis (pp. 557-570). Sevilla: Grupo de Población de la Asociación de Geógrafos Españoles.

Roca Cladera, J., Moix Bergadá, M., \& Arellano Ramos, B. (2012). El sistema urbano en España. Scripta Nova, XVI(396). Retrieved from http://www.ub.es/geocrit/sn/sn-384.htm

Recaño, J. (2002). La movilidad geográfica de la población extranjera en España. Un fenómeno emergente. Cuadernos de Geografía, 72, 135-156.

Recaño, J. (2009a). La movilidad geográfica de la población extranjera en España: factores sociodemográficos y territoriales. In J.J. Pons et al. (Eds.), Territorio y movilidad interior de la población en España (pp. 149-160). Pamplona: Eunsa.

Recaño, J. (2009b). Inmigración exterior y transformaciones de las migraciones internas en España. Paper presented at the XXXV Reunión de Estudios Regionales. Valencia. Retrieved from http://old.reunionesdeestudiosregionales.org/valencia2009/htdocs/pdf/p231.pdf

Susino. J. (2012). Fuentes demográficas para el estudio de la migración en España. Revista Interdisciplinar da Mobilidade Humana, XX(39), 51-76.

Van Dalin, H. P., \& Hinkins, K. (2012). Explaining low international labour mobility: The role of networks, personality, and perceived labour market opportunities. Population, Space and Place, 18(1), 31-44. 